\title{
Study and apply the advanced analysis algorithm to screen the optimal enhanced oil recovery solution for oil and gas fields in Viet Nam
}

\author{
Long Hoang 1,*, Thang Viet Trinh ${ }^{2}$, Truong Hung Trieu ${ }^{3}$, Quy Minh Nguyen ${ }^{1}$, Ngoc \\ Quy Pham ${ }^{1}$, Hien Huy Doan ${ }^{1}$, Linh Hoang ${ }^{1}$ \\ 1 Vietnam Petroleum Institute, Hanoi, Vietnam \\ 2 Vietnam Oil and Gas Group, Hanoi, Vietnam \\ ${ }^{3}$ Hanoi University of Mining and Geology, Hanoi, Vietnam
}

ARTICLE INFO

Article history:

Received 18 ${ }^{\text {th }}$ Feb. 2021

Revised 29 ${ }^{\text {th }}$ May 2021

Accepted $20^{\text {th }}$ June 2021

Keywords:

EOR analysis algorithm,

EOR Clustering,

EOR screening criteria,

EOR screening methodology.

\section{ABSTRACT}

Applying the methods of enhanced oil recovery (EOR) for oil and gas fields has always many risks of economic and technology because EOR projects are influenced by many characteristic factors of the reservoir such as structure of reservoir, reservoir formation, geological properties, parameters of reservoir engineering, production technology to EOR application. Some EOR methods have been successfully applied in the world, but when these methods conduct in specific reservoir with different geological characteristics, tight production conditions have resulted in failures and ineffective economic, even caused dreadful aftermath to be handled in operations. Researches, evaluations and EOR applications in Vietnam are limited and only carried out on a laboratory scale. Therefore, the ability to be applied the EOR modern technology with a large scale or full field still faces many difficulties and the feasibility of projects is not high enough. The authors have been analysed all EOR projects successfully that applied many oil and gas fields in the world and then building EOR database. Based on EOR database, a study has been conducted on statistical analysis to build EOR screening criteria for reservoir parameters from past to now. The study also combined in-depth analysis algorithms such as Fuzzy, $K$ - mean, PCA Artificial Intelligence to screen the optimal EOR method for sandstone reservoirs of Cuu Long Basin.

Copyright (C) 2021 Hanoi University of Mining and Geology. All rights reserved.

${ }^{*}$ Corresponding author 


\title{
Tạp chí Khoa học Kỹ thuật Mỏ - Địa chất
}

Trang điện tử: http://tapchi.humg.edu.vn

\section{Nghiên cứu và áp dụng thuật toán phân tích chuyên sâu để lựa chọn giải pháp EOR tối ưu cho các mỏ dầu khí ở Việt Nam}

\author{
Hoàng Long ${ }^{1 *}$, Trịnh Việt Thắng², Triệu Hùng Trường ${ }^{3}$, Nguyễn Minh Quý ${ }^{1}$, Phạm \\ Quy Ngọc ${ }^{1}$, Đoàn Huy Hiên ${ }^{1}$, Hoang Linh ${ }^{1}$ \\ ${ }^{1}$ Viện Dầu Khí Việt Nam, Hà Nội, Việt Nam \\ 2 Tập đoàn Dầu khí Việt Nam, Hà Nội, Việt Nam \\ 3 Trường Đại học Mỏ - Địa chất, Hà Nội, Việt Nam
}

\begin{tabular}{|c|c|}
\hline THÔNG TIN BÀI BÁO & TÓM TĂT \\
\hline $\begin{array}{l}\text { Quá trình: } \\
\text { Nhận bài 18/02/2021 } \\
\text { Sửa xong 29/5/2021 } \\
\text { Chap nhận đăng 20/6/2021 }\end{array}$ & 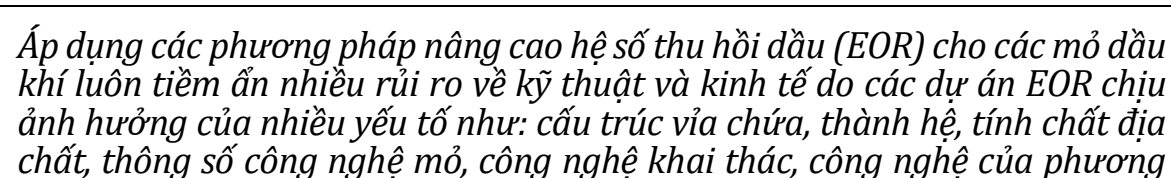 \\
\hline $\begin{array}{l}\text { Tùr khóa: } \\
\text { Nâng cao hệ số thu hồi } \\
\text { dầu, } \\
\text { Phân tích chuyên sâu, } \\
\text { Phương pháp chuyên gia, } \\
\text { Thuật toán phân cụm, } \\
\text { Tiêu chí lựa chọn. }\end{array}$ & 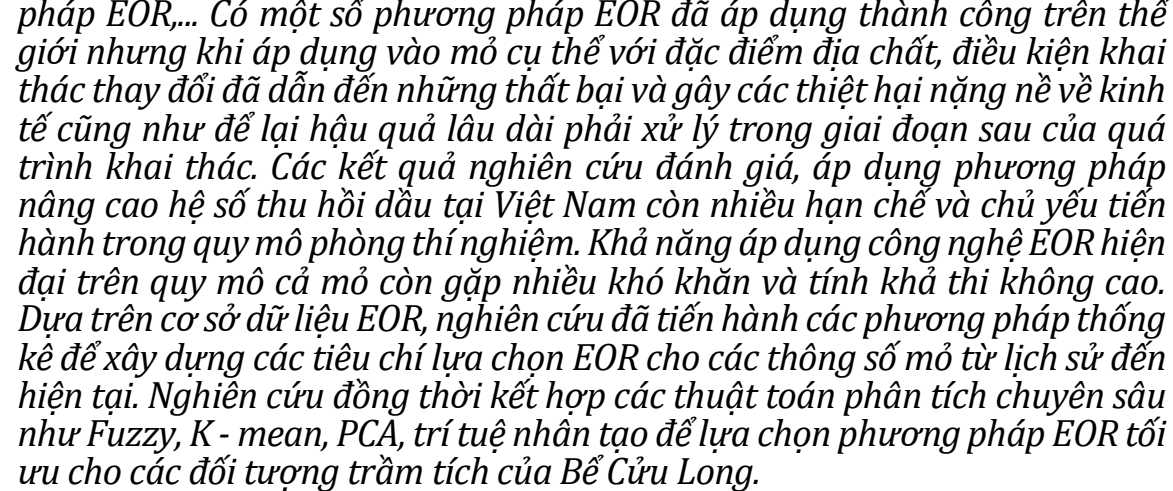 \\
\hline
\end{tabular}

C 2021 Trường Đại học Mỏ - Địa chất. Tất cả các quyền được bảo đảm.

\section{Mở đầu}

Trong những năm gần đây, sản lượng khai thác dầu của Việt Nam đang suy giảm rất nhanh do một số mỏ có trữ lượng dầu khí lớn đang đi vào quá trình khai thác cuối đời mỏ, tận thu khai thác.

\section{${ }^{*}$ Tác giả liên hệ}

E-mail: longh@vpi.pvn.vn

DOI: 10.46326/JMES.2021.62(3a).03
Trong khi đó, số lượng các mỏ dầu khí mới phát hiện không nhiều và đa phần là các mỏ có trữ lượng thu hồi dầu khí nhỏ, cận biên và có điều kiện khai thác khó khăn dẫn đến đầu tư phát triển gặp rủi ro cao về hiệu quả của dự án. Các kết quả phân tích và dự báo khai thác cho các mỏ dầu cho thấy, đến sau năm 2024 sản lượng khai thác chỉ còn khoảng 10 triệu tấn/năm và đến năm 2035 là dưới 2 triệu tấn/năm nếu không có các mỏ mới đưa vào khai thác (Hoàng Long và nnk., 2021). 
Do đó, việc triển khai áp dụng các phương pháp nâng cao hệ số thu hồi dầu (EOR) trên các mỏ dầu khí là vấn đề rất cấp bách hiện nay.

Các nghiên cứu trong và ngoài nước đều chỉ ra rằng áp dụng các phương pháp EOR trong các dự án EOR trên thế giới luôn tiềm ẩn nhiều rủi ro về kinh tế và kỹ thuật do chịu nhiều ảnh hưởng từ cấu trúc vỉa, địa chất, công nghệ mỏ - khai thác. Do đó, việc tiến hành đánh giá, phân tích chi tiết các thông số kỹ thuật của mỏ kết hợp với các kinh nghiệm đã áp dụng thành công thực tế sẽ giúp lựa chọn được giải pháp công nghệ có tính khả thi, phù hợp với trang thiết bị hiện có của mỏ, giảm chi phí, giảm thiểu các rủi ro về kỹ thuật khi áp dụng cho mỏ dầu khí. Ngay trong một số mỏ dầu khí được khai thác từ nhiều đối tượng có cùng cấu trúc và công nghệ khai thác thác nhưng tính chất địa chất, thạch học, chất lưu khác nhau cũng sẽ dẫn đến việc áp dụng các giải pháp EOR riêng biệt cho từng đối tượng (Hoàng Long và nnk., 2021). Ngoài ra, bài toán khả thi giữa kỹ thuật và hiệu quả kinh tế phải được nghiên cứu và phân tích đồng thời để đảm bảo thành công của dự án.

Nghiên cứu, lựa chọn giải pháp và phát triển ứng dụng nâng cao hệ số thu hồi dầu là một phần trong kế hoạch phát triển ban đầu với bất kỳ một mỏ dầu khí nào. Trong giai đoạn thứ cấp, đa số các mỏ dầu khí đều sử dụng bơm ép nước để duy trì áp suất vỉa và gia tăng sản lượng khai thác trong giai đoạn khai thác tự nhiên đầu đời mỏ. Nước bơm ép có độ linh động cao hơn dầu vỉa sẽ có khả năng chảy thẳng từ giếng bơm ép đến giếng khai thác theo các kênh dẫn có độ thấm lớn, hay còn gọi là hiệu ứng trượt sườn hoặc tạo thành các lưỡi nước trong vỉa dầu, dẫn đến độ ngập nước cao trong các giếng khai thác và hệ số dầu tàn dư trong vỉa lớn. Tỷ số nước - dầu trong giếng khai thác tăng cao sẽ làm giảm hiệu quả khai thác dầu, tăng chi phí xử lý nước khai thác, dẫn đến không có hiệu quả về kinh tế, đặc biệt nhiều giếng phải dừng khai thác và tiến hành hủy bỏ giếng. Các phương pháp EOR được áp dụng để nâng cao lượng dầu thu hồi và giảm độ ngập nước của các giếng khai thác và toàn bộ mỏ đang khai thác. Lựa chọn phương pháp nâng cao hệ số thu hồi phù hợp và hiệu quả gồm có các phương pháp chính như: bơm ép khí, bơm ép chất lưu đẩy bằng các tổ hợp hóa học, phương pháp nhiệt đều phụ thuộc hoàn toàn vào tính chất của vỉa chứa như cấu trúc vỉa chứa, tính chất địa chất, các thông số công nghệ mỏ, thông số giếng, công nghệ khai thác và cơ sở hạ tầng của khu vực mỏ. Để đánh giá được các yếu tố ảnh hưởng đến hiệu quả của các phương pháp, cần tiến hành nghiên cứu từ nguyên lý cơ bản đến chi tiết các cơ chế của phương pháp EOR để có thể lựa chọn được giải pháp và công nghệ áp dụng hiệu quả cho các mỏ dầu khí.

Trong công nghệ dầu khí, việc lựa chọn giải pháp EOR tối ưu thông thường sử dụng phương pháp tham khảo từ các mỏ đã áp dụng EOR thành công trên thế giới, để từ đó xác định giải pháp EOR tiềm năng và hiệu quả cho đối tượng đang nghiên cứu. Trong phạm vi bài báo này này, dựa trên cơ sở dữ liệu (CSDL) của các dự án EOR thành công trên thế giới, nhóm tác giả đã tiến hành phân tích, đánh giá thống kê và sử dụng các thuật toán chuyên sâu để lựa chọn các giải pháp EOR tối ưu. Việc lựa chọn dựa trên 3 phương pháp:

i) Phương pháp nghiên cứu đánh giá thông thường với các thông số vỉa của mỏ so sánh với bảng tiêu chí được thu thập từ CSDL của các dự án EOR đã áp dụng thành công. Phương pháp này thường được xây dựng trên các tiêu chí từ CSDL và so sánh trọng số với các thông số mỏ nghiên cứu, từ đó đưa ra phương pháp EOR tối ưu (Taber và nnk., 1997);

ii) Phương pháp chuyên sâu dựa trên các thuật toán về học máy, Fuzzy, PCA phân tích cấu tử chính, $\mathrm{K}$ - mean và clustering để lựa chọn giải pháp tối ưu nhất. Các phân tích và đánh giá ở trên cuối cùng được sàng lọc và lựa chọn trên các kinh nghiệm của chuyên gia (Zhang, 2015);

iii) Phương pháp chuyên gia được xây dựng dựa trên các kinh nghiệm thực tiễn, thông số mỏ và hiện trạng thiết bị hiện có đã được số hóa để đưa ra kết luận cuối cùng cho giải pháp EOR tối ưu (Guerillot, 1988). Các thông số mỏ của các đối tượng thuộc trầm tích Bể Cửu Long đã được đưa vào tính toán và chạy thử nghiệm trên các thanh công cụ theo phương pháp đánh giá thông thường, đánh giá chuyên sâu và chuyên gia để lựa chọn giải pháp phù hợp, tối ưu, đảm bảo hiệu quả cho từng đối tượng của trầm tích Bể Cửu Long. Kết quả đưa ra từ nghiên cứu với các đối tượng chạy thử nghiệm rất phù hợp với phân tích và nhận định của các chuyên gia và nhà thầu điều hành mỏ hiện tại ở Việt Nam.

\section{Cơ sở lý thuyết và phương pháp nghiên cứu}

Trong ngành công nghiệp dầu mỏ, quy trình 
lựa chọn giải pháp EOR tối ưu cho mỏ được coi là bước đầu tiên để tiến hành áp dụng các giải pháp EOR cho mỏ. Từ những năm 1970, nhiều phương pháp lựa chọn EOR đã được nghiên cứu và đề xuất để có thể tìm ra phương pháp EOR phù hợp, tối ưu đối với một vỉa chứa (Al - Adasani và Bai, 2010). Năm 1978, Poettmann và Hause đề xuất tiêu chí lựa chọn bơm ép tổ hợp micellar - polyme xuống mỏ dầu dựa trên tính chất đặc trưng của vỉa, đây là nghiên cứu được công bố đầu tiên về nghiên cứu lựa chọn và áp dụng EOR (Poettmann và Hause, 1978). Sau đó, đặc biệt là từ cuối những năm 1990, các tiêu chí lựa chọn giải pháp EOR cho các quá trình áp dụng EOR đã được nghiên cứu rộng hơn và đã được nhiều nhà nghiên cứu thảo luận, trao đổi. Có rất nhiều phương pháp luận đã được phát triển dựa trên kinh nghiệm và nghiên cứu của các nhà khoa học dầu khí và các nhà điều hành mỏ $(\mathrm{Al}$ - Adasani và Bai, 2010). Các nhà khoa học và các công trình nghiên cứu đã tổng hợp các dự án EOR áp dụng thử nghiệm trên phạm vi pilot và phạm vi toàn mỏ để phân tích các yếu tố ảnh hưởng, ưu nhược điểm của từng phương pháp, hiệu quả áp dụng, để có thể xây dựng được các tiêu chí lựa chọn. Các dữ liệu được xây dựng thành các CSDL để phục vụ cho các nhà điều hành và các nhà nghiên cứu về EOR trong việc lựa chọn phương pháp phù hợp áp dụng thực tế. Trên các CSDL ngày một lớn do các dự án EOR được áp dụng trong nhiều năm, các nhà khoa học đã áp dụng các thuật toán phân tích, thống kê, trọng số hóa để xác định được các ảnh hưởng của thông số mỏ đến mức độ thành công và tính khả thi khi áp dụng của dư án EOR.

Cho đến nay, các phương pháp để lựa chọn giải pháp EOR phù hợp cho mỏ nghiên cứu có thể được tổng hợp và phân loại thành 3 phương pháp như đã trình bày ở trên. Để có thể phân tích, đánh giá và lựa chọn được giải pháp EOR tối ưu đều phải dựa trên CSDL của các dự án EOR đã áp dụng trên thế giới và Việt Nam. CSDL của nghiên cứu này đã thu thập được khoảng trên 5.000 trường dữ liệu đại diện cho khoảng 950 dự án EOR theo thời gian triển khai từ năm 1986 đến nay, mỗi trường có 28 thông số đại diện cho dự án.

\subsection{Phương pháp thông thường}

Phương pháp tham khảo và so sánh hoặc phương pháp thông thường hay còn được gọi là phương pháp tiếp cận “đi/không đi”, thường sử dụng với phạm vi số liệu nhỏ của các đặc tính/tính chất của vỉa chứa hoặc tính chất chất lưu vỉa và chất lưu bơm đẩy để lựa chọn ra các công nghệ EOR áp dụng tối ưu. Các bảng tra cứu/các tiêu chí đến từ các nghiên cứu phân tích thống kê của các dự án EOR đã áp dụng hiện có. Các tiêu chí được cung cấp với các khoảng cho các tính chất/đặc tính khác nhau cho từng phương pháp EOR. Bảng tiêu chí và các khoảng thông số lựa chọn cho các giải pháp EOR nổi tiếng và được các nhà khoa học thừa nhận đầu tiên là của Taber và các công sự đưa ra vào năm 1997. Taber đưa ra các tiêu chí lựa chọn dựa trên các dự án EOR được thực hiện từ năm 1974 đến năm 1996 (Taber và nnk., 1997). Sáu thông số quan trọng đã được xem xét trong quá trình lựa chọn được đề xuất với các khoảng thông số phù hợp, bao gồm: tỷ trọng của dầu vỉa, độ nhớt của vỉa dầu, độ bão hòa dầu, độ thấm trung bình, độ sâu và nhiệt độ. Sau đó, $\mathrm{Al}$ - Adasani và Bai đã cập nhật khoảng các tiêu chí lựa chọn của Taber với các thông số phân tích thống kê CSDL từ năm

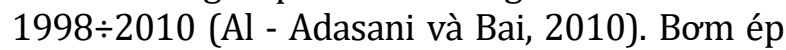
trộn lẫn và không trộn lẫn được áp dụng cho tất cả các công nghệ bơm ép khí và thêm tiêu chí về độ rỗng được bổ sung vào công trình nghiên cứu của họ. Mặc dù cả Taber và $\mathrm{Al}$ - Adasani đều cung cấp các bảng tiêu chí hữu ích cho từng phương pháp, việc cập nhật các tiêu chí lựa chọn với sự cập nhật các dự án EOR ngày càng gia tăng mạnh mẽ trên thế giới là rất quan trọng. Vì các tiêu chí lựa chọn thông thường chỉ được xây dựng dựa trên các dự án hiện có và kiến thức chuyên môn của các chuyên gia tại thời điểm đó, không có quá trình cập nhật công nghệ theo thời gian. Do đó, quá trình nghiên cứu và cập nhật các tiêu chí lựa chọn bằng cách xây dựng CSDL của dự án theo thời gian từ những thập kỷ trước đến nay đóng vai trò then chốt cho kết quả nghiên cứu. Phương pháp lựa chọn thông thường sẽ gặp khó khăn do hạn chế của các tiêu chí không được cập nhật theo thời gian và thông tin chi tiết các đặc thù của từng vỉa hoặc mỏ dầu khí. Một số phương pháp EOR có các tiêu chí và khoảng làm việc của các tiêu chí khá giống nhau nên sẽ đưa ra nhiều giải pháp EOR cho 1 mỏ nghiên cứu. Điều này gây khó khăn cho nhà điều hành khi quyết định tiến hành áp dụng giải pháp EOR cho mỏ. Vì vậy, các nhà khoa học đã sử dụng phương pháp lựa chọn nâng cao với các thuật toán, công nghệ tin học, để lựa chọn giải pháp tối ưu nhất EOR cho mỏ nghiên cứu 
(Guerillot, 1988). Sử dụng kết quả xây dựng bộ tiêu chí từ CSDL đối chiếu bằng phương pháp toán học với các thông số của mỏ nghiên cứu sẽ đưa ra sự lựa chọn phương pháp có thể áp dụng tối ưu nhất.

\subsection{Phương pháp nghiên cứu chuyên sâu}

Phương pháp nghiên cứu chuyên sâu hay còn gọi là lựa chọn EOR nâng cao bao gồm tất cả các phương pháp áp dụng các thuật toán Fuzzy, PCA, $K$ - mean, phân nhóm bằng clustering để hỗ trợ lựa chọn giải pháp EOR tối ưu dựa trên các phân tích toán học về mối tương quan, tính chất tương tự hoặc tương đồng với các khoảng thông số mỏ với nhau (Zhang, 2015). Nguyên lý được xác định bởi khoảng cách vật lý (như Euclidean, Manhattan, Jaccard,...) hoặc khoảng cách xác suất (Ramos và Akanji, 2017). Các phương pháp trí tuệ nhân tạo cho kết quả với sự chính xác và tin cậy cao hơn trong nghiên cứu lựa chọn EOR. Các thuật toán có khả năng tìm ra các mẫu ẩn trong việc triển khai các kỹ thuật EOR, xác định mối quan hệ giữa các đặc tính của vỉa chứa/chất lưu và hỗ trợ dự đoán cho nhiều quy mô áp dụng trên mỏ thực tế hoặc các tính chất vật lý của giải pháp EOR. Alvarado và các cộng sự đã đề xuất phương pháp sử dụng thuật toán học máy để rút ra các quy tắc cho việc lựa chọn EOR (Al - Adasani và Bai, 2010). Sáu cụm thông số theo các tiêu chí được phân loại dựa trên tập dữ liệu và mỗi cụm có quy tắc riêng cho các ứng dụng giải pháp EOR. Siena và cộng sự đã tiếp tục phát triển phương pháp tương tự các vỉa chứa bằng cách áp dụng thuật toán phân cụm phân cấp Bayes (Siena và Guadagnini, 2016). Mặc dù các phương pháp EOR nâng cao cung cấp các kết quả phân biệt hoặc lựa chọn dựa trên việc tính toán các điểm tương đồng trong mỗi thuật toán, độ tin cậy và độ chính xác của các mô hình dự đoán và lựa chọn cần được các chuyên gia nghiên cứu và xác nhận thêm bằng cách sử dụng các thử nghiệm trên mô hình mô phỏng khai thác và thực nghiệm trong phòng thí nghiệm.

Để có thể xây dựng được chức năng lựa chọn giải pháp EOR tối ưu bằng phương pháp nâng cao, cần tiến hành cập nhật các bảng tiêu chí lựa chọn dựa trên CSDL đã được xây dựng và tiến hành trích xuất tất cả các trường dữ liệu của CSDL để tạo ma trận số liệu phục vụ các phân tích chuyên sâu của các thuật toán.

\subsection{Phương pháp chuyên gia}

Đây là phương pháp sử dụng CSDL của các dự án thành công trên thế giới kết hợp với các phân tích chuyên sâu của các chuyên gia với điều kiện mỏ thực tế để lựa chọn phương pháp EOR phù hợp cho các mỏ dầu khí nghiên cứu (Guerillot, 1988).

Phương pháp chuyên gia sẽ lựa chọn các tiêu chí cứng ngay từ đầu của quá trình sàng lọc. Các thông tin, thông số mỏ như: trữ lượng dầu còn lại, trữ lượng dầu tại chỗ, sản lượng khai thác, hệ thống khai thác, vận chuyển và xử lý của mỏ nghiên cứu được sàng lọc để áp dụng như một tiêu chí sơ bộ để loại các dự án. Ngoài ra, phương pháp chuyên gia còn đánh giá hiệu quả kinh tế của mỏ khi áp dụng phương pháp nâng cao hệ số thu hồi dầu cụ thể cũng như xác định khả năng áp dụng giải pháp ngoài thực tế như nguồn chất lưu để bơm ép có khả thi.

Trong nghiên cứu này, các tác giả đã xây dựng một bộ CSDL gồm nhiều trường dữ liệu đại diện cho 950 dự án EOR theo thời gian triển khai (Hoàng Long và nnk., 2020), mỗi trường có các thông số đại diện cho dự án như: vị trí địa lý, đối tượng địa chất, tính chất hình học của cấu trúc vỉa chứa, độ rỗng, độ thấm, thành phần thạch học đá via, tính chất chất lưu vỉa, thành phần dầu vỉa, thành phần nước vỉa, nhiệt độ, áp suất, công nghệ khai thác áp dụng, sản lượng khai thác, số giếng khai thác, số giếng bơm ép, sản lượng gia tăng khi áp dụng EOR, đánh giá dự án của các chuyên gia và mức độ thành công của dự án,...

Nghiên cứu đã xây dựng được CSDL các dự án EOR trên thế giới và phát triển xây dựng thành phần mềm VPI EOR Screening với các thanh công cụ để phân tích số liệu gồm các phân tích theo phương pháp thông thường dựa trên tham khảo và so sánh với cơ sở dự liệu và các thông số mỏ nghiên cứu đến phương pháp nâng cao bằng các nghiên cứu chuyên về các phương pháp toán học để xử lý/phân tích số liệu như PCA - phân tích thành phần chính, $K$ - mean để lựa chọn các cụm cho đối tượng nghiên cứu, thuật toán phân cụm (clustering), học máy để xác định và lựa chọn giải pháp EOR tối ưu nhất với mỏ nghiên cứu đã được đưa ra và áp dụng thành công (Hình 1 ).

\section{Kết quả, phân tích kết quả, thảo luận}

CSDL và phần mềm với các công cụ toán học 

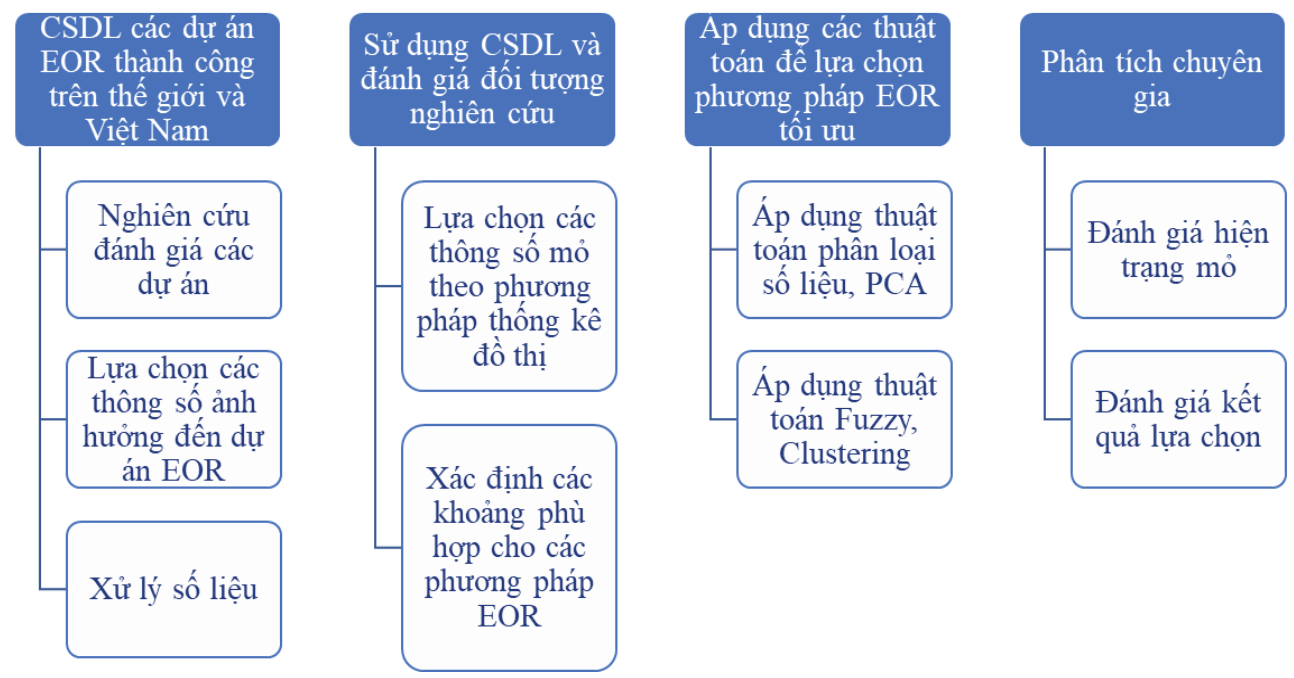

Hình 1. Phương pháp tổng hợp xây dựng CSDL và các phương pháp phân tích lựa chọn giải pháp EOR tối ư cho mỏ dầu khí.

để phân tích và lựa chọn dự án EOR tối ưu cho các mỏ dầu khí đã được nghiên cứu và xây dựng thành công. Dựa trên CSDL đã xây dựng của các dự án EOR đã áp dụng trên thế giới, các biểu đồ theo các tiêu chí được xây dựng để đánh giá và lựa chọn. Các thông số được đánh giá và nghiên cứu bao gồm: độ rỗng, độ thấm, độ sâu, tỷ trọng API, độ nhớt dầu, nhiệt độ vỉa, bão hòa dầu, sản lượng gia tăng khi áp dụng EOR, kết quả đánh giá hiệu quả của dự án. Các phương pháp nghiên cứu chuyên sâu dựa trên phân tích CSDL bằng các thuật toán Fuzzy, PCA - phân tích thành phần chính, hệ thống hàm phân lọc, thuật toán phân cụm, học máy để xác định phương pháp EOR phù hợp nhất với mỏ nghiên cứu.

Dựa trên các trường dữ liệu và các thông tin về dự án EOR đã thu thập, nghiền cứu đã xây dựng được một CSDL trên phần mềm chuyên dụng cho phép tra cứu, truy xuất các thông tin của gần 950 dự án theo thời gian bắt đầu áp dụng đến khi kết thúc dự án. Các thông tin được sắp xếp theo thứ tự từ thông tin địa lý, tính chất vỉa chứa, địa chất, công nghệ mỏ, các phương pháp khai thác sơ cấp, phương pháp khai thác thứ cấp đến các đánh giá hiệu quả của dự án cũng như các thông tin về sản lượng dầu khai thác gia tăng, độ ngập nước và bão hòa dầu dư khi áp dụng các phương pháp EOR. Các báo cáo EOR chi tiết gồm tất cả các thông tin, đánh giá và kết quả áp dụng của dự án sẽ giúp các nhà nghiên cứu có thể vận dụng, hoặc tìm kiếm các kinh nghiệm để có thể hạn chế các rủi ro khi áp dụng phương pháp EOR tối ưu cho mỏ đang nghiên cứu. Các số liệu và báo cáo có thể truy xuất hoặc trích xuất trực tiếp trên CSDL để tạo thành các file đầu vào cho phần mềm VPI EOR Screening giúp lựa chọn giải pháp EOR tối ưu hoặc sử dụng để nghiên cứu chuyên sâu cho các dự án EOR sẽ áp dụng ở Việt Nam nói riêng và thế giới nói chung (Hình 2). Phần mềm VPI EOR Screening gồm các phương pháp nghiên cứu đánh giá thông thường với việc xây dựng các tiêu chí dựa trên CSDL thu thập và xây dựng các giới hạn, trọng số của các thông số ảnh hưởng lẫn nhau để lựa chọn được phương pháp EOR phù hợp có các thông số gần với mỏ nghiên cứu nhất. Bộ thông số áp dụng thông thường bao gồm: tỷ trọng của dầu, độ nhớt của dầu, độ thấm - độ rỗng trung bình vỉa, độ sâu và nhiệt độ. Phương pháp thông thường sau này được bổ sung thêm các nghiên cứu chuyên gia giúp nâng cao chất lượng xác định giải pháp phù hợp. Phần mềm cũng gồm phần nghiên cứu lựa chọn nâng cao là các thanh công cụ, nghiên cứu chuyên sâu về các phương pháp toán học để xử lý/phân tích số liệu như trí tuệ nhân tạo, PCA phân tích thành phần chính, $K$ - mean để lựa chọn các cự cho đối tượng nghiên cứu, thuật toán phân cụm (clustering), học máy, để xác định giải pháp EOR tối ưu nhất với mỏ nghiên cứu. Các phương pháp toán học lập trình và tích hợp vào phần mềm VPI EOR Screening để các nhà nghiên cứu có thể sử dụng chủ động trên các file CSDL.

Kết quả thống kê và hiệu chỉnh số liệu đầu vào được thực hiện trên thanh công cụ của CSDL và cho kết quả như trong Hình 3. 


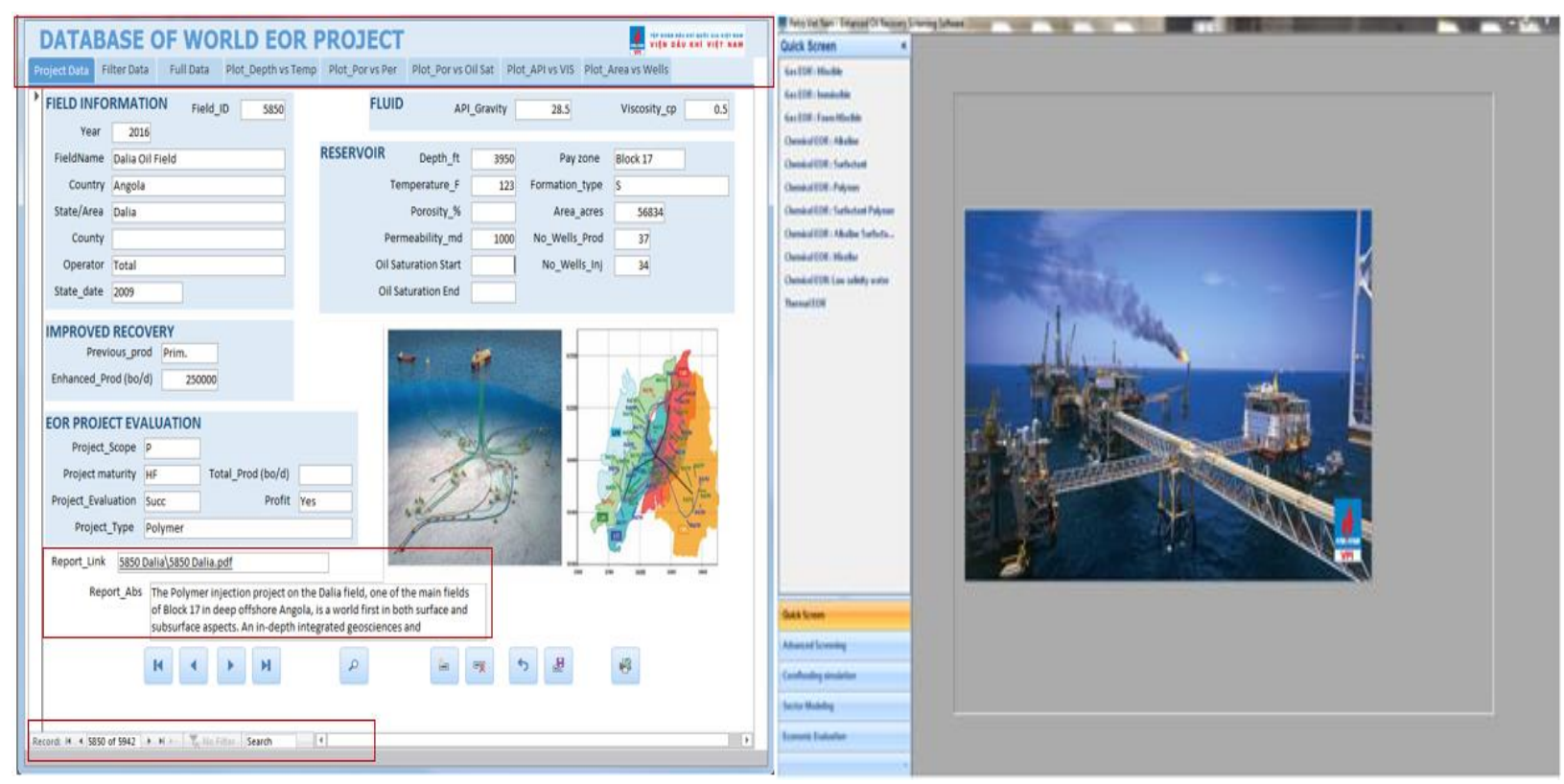

Hình 2. CSDL và phần mềm VPI EOR Screening (Hoàng Long và nnk., 2020).
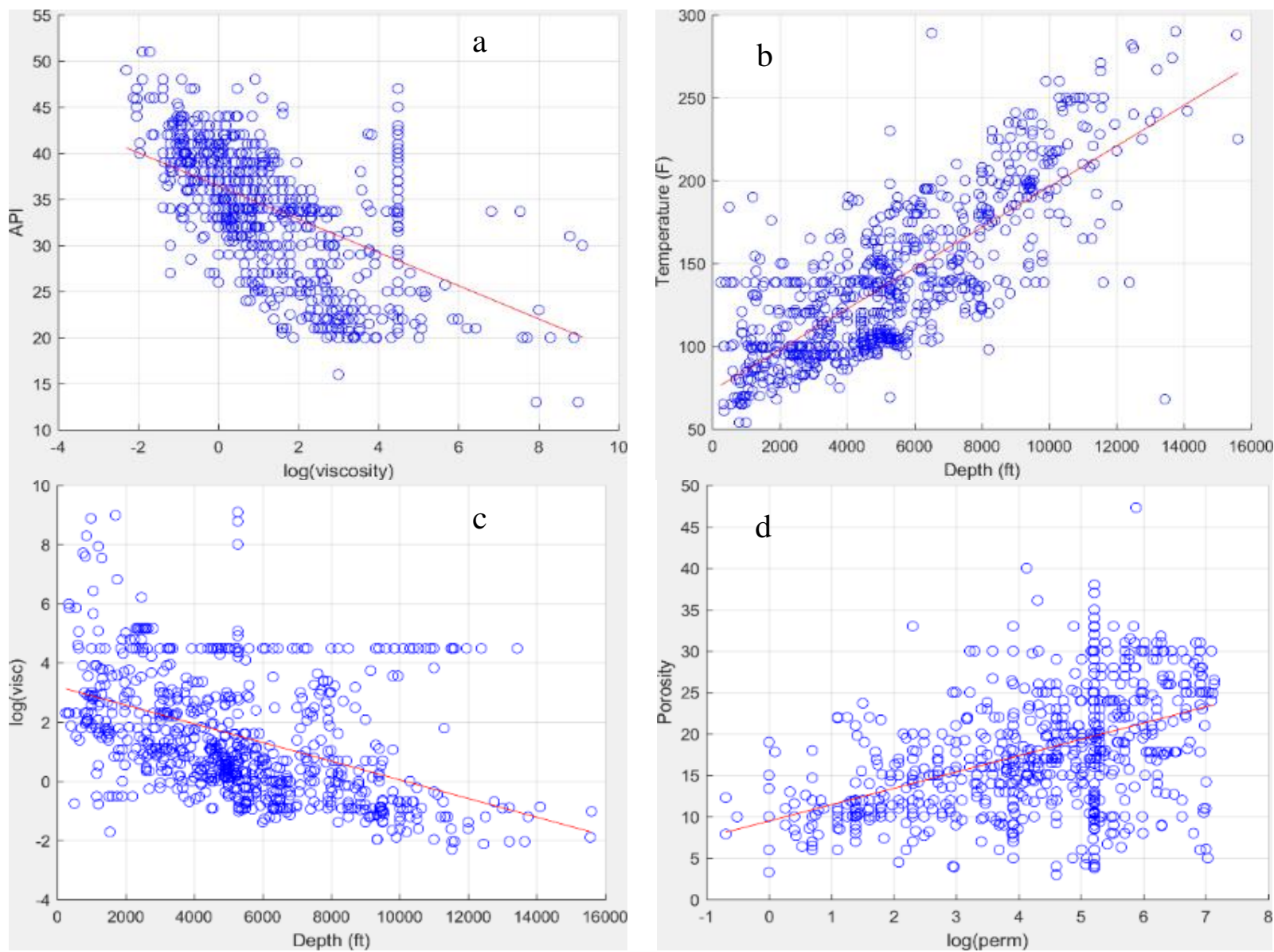

Hình 3. Thống kê các thông số đầu vào tù̀ CSDL với mối tương quan giữa tỷ trọng với độ nhớt (a); nhiệt độ và độ sâu (b); độ nhớt và độ sâu (c); độ rỗng và độ thấm (d). 
Một số thông số không phù hợp với các đối tượng nghiên cứu là các mỏ dầu trong Bể Cửu Long sẽ được loại bỏ trong các phân tích và đánh giá lựa chọn chuyên sâu. Quá trình xử lý số liệu được thực hiện trên phần mềm VPI EOR Screening như trong Hình 4.

Để đánh giá kết quả nghiên cứu từ các thuật toán tích hợp trong phần mềm, các thông số cơ bản của một số mỏ dầu khí đang khai thác ở trầm tích Bể Cửu Long, Việt Nam được đưa vào phần mềm (Bảng 1). Các thông số vỉa như độ rỗng, độ thấm có giá trị biến thiên rất lớn do tính chất vỉa có tính bất đồng nhất cao nên việc phân tích chuyên sâu được thực hiện với các khoảng độ rỗng, độ thấm từ nhỏ nhất, trung bình, cao nhất. Các thông số khác ít thay đổi thì được lấy trung bình để giảm thiểu các tính toán.

\subsection{Kết quả tính toán theo phưong pháp thông thường (Quick screening)}

Các thông số thể hiện tính chất vỉa như: độ sâu, nhiệt độ, độ rỗng, độ thấm, độ bão hòa dầu hiện tại và các thông số chất lưu như: độ nhớt dầu vỉa, tỷ trọng dầu vỉa của các đối tượng thuộc Mioxen Bạch Hổ cho thấy sự biến thiên hoặc thay đổi giữa các mỏ, các đối tượng là không nhiều. Độ sâu từ khoảng $2.100 \div 3.000$ m, độ rỗng trung bình từ khoảng $18 \div 26 \%$, độ thấm trung bình khoảng $160 \div 560 \mathrm{mD}$, độ bão hòa dầu hiện tại của các đối tượng đều khoảng 40 $50 \%$, độ nhớt trung bình đều khoảng $0,7 \div 4$ cp, tỷ trọng từ $29 \div 37$ oAPI. Kết quả tính toán từ phần mềm cho thấy sự thay đổi của các phương pháp đối với các đối tượng trầm tích Bể Cửu Long là không quá lớn (Hình 5).
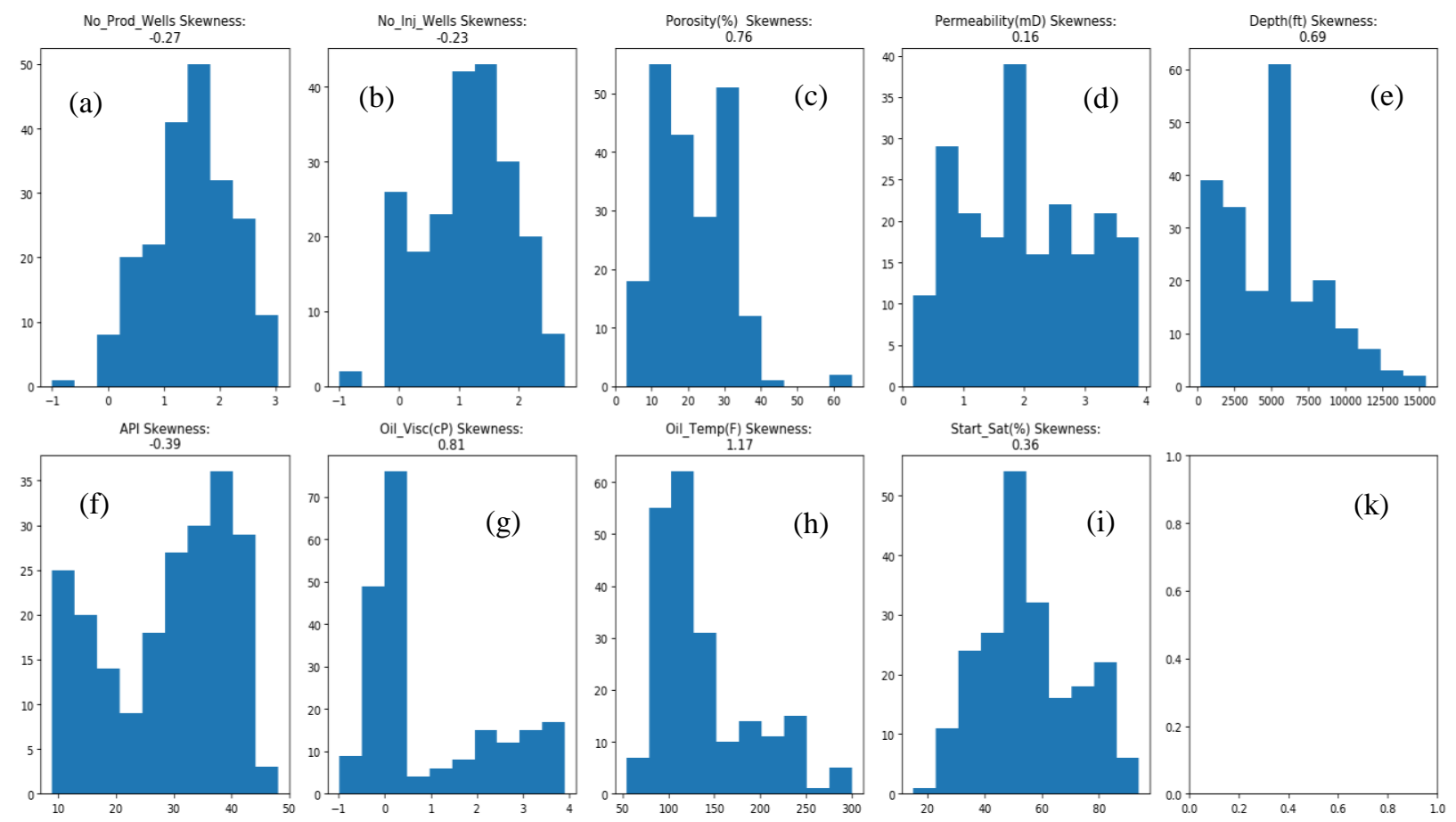

Hình 4. Kết quả xử lý số liệu đầu vào được xuất tù̀ CSDL với sự phân bố tương quan của giếng khai thác (a); giếng bơm ép (b); độ rỗng (c); độ thấm (d); độ sâu (e); tỷ trọng (f); độ nhót dầu (g); nhiệt độ (g); độ bão hòa (i); thông số trắng $(k)$.

Bảng 1. Các thông số cơ bản chính sử dụng đầu vào của các mỏ dầu khí Bể Cửu Long (Hoàng Long và nnk., 2021).

\begin{tabular}{|c|c|c|c|c|c|c|c|}
\hline \multirow[b]{2}{*}{ Mỏ } & \multicolumn{5}{|c|}{ Tính chất vỉa chứa } & \multicolumn{2}{|c|}{ Tính chất lưu thể } \\
\hline & $\begin{array}{c}\text { Độ sâu } \\
\text { (m) }\end{array}$ & $\begin{array}{c}\text { Nhiệt độ } \\
(\mathrm{oF})\end{array}$ & $\begin{array}{l}\text { Độ thấm } \\
\text { (mD) }\end{array}$ & $\begin{array}{c}\text { Độ rỗng } \\
(\%)\end{array}$ & $\begin{array}{c}\text { Bão hòa dầu } \\
(\%)\end{array}$ & $\begin{array}{l}\text { Tỷ trọng } \\
\text { (API) }\end{array}$ & $\begin{array}{l}\text { Độ nhớt } \\
\text { (cP) }\end{array}$ \\
\hline A & 3.000 & $80 \div 100$ & $20 \div 380,(\mathrm{~Tb}=160)$ & $9 \div 30(18)$ & 50 & 29 & $2 \div 5(4)$ \\
\hline B & 2.700 & $85 \div 100$ & $70 \div 530(\mathrm{~Tb}=185)$ & $9 \div 31(23,2)$ & 50 & 37,9 & $0,6 \div 0,9(0,7)$ \\
\hline $\mathrm{C}$ & 2.100 & $75 \div 90$ & $80 \div 1950(\mathrm{~Tb}=560)$ & $9 \div 33(26)$ & 40 & 35,4 & $0,65 \div 0,95(0,8)$ \\
\hline
\end{tabular}



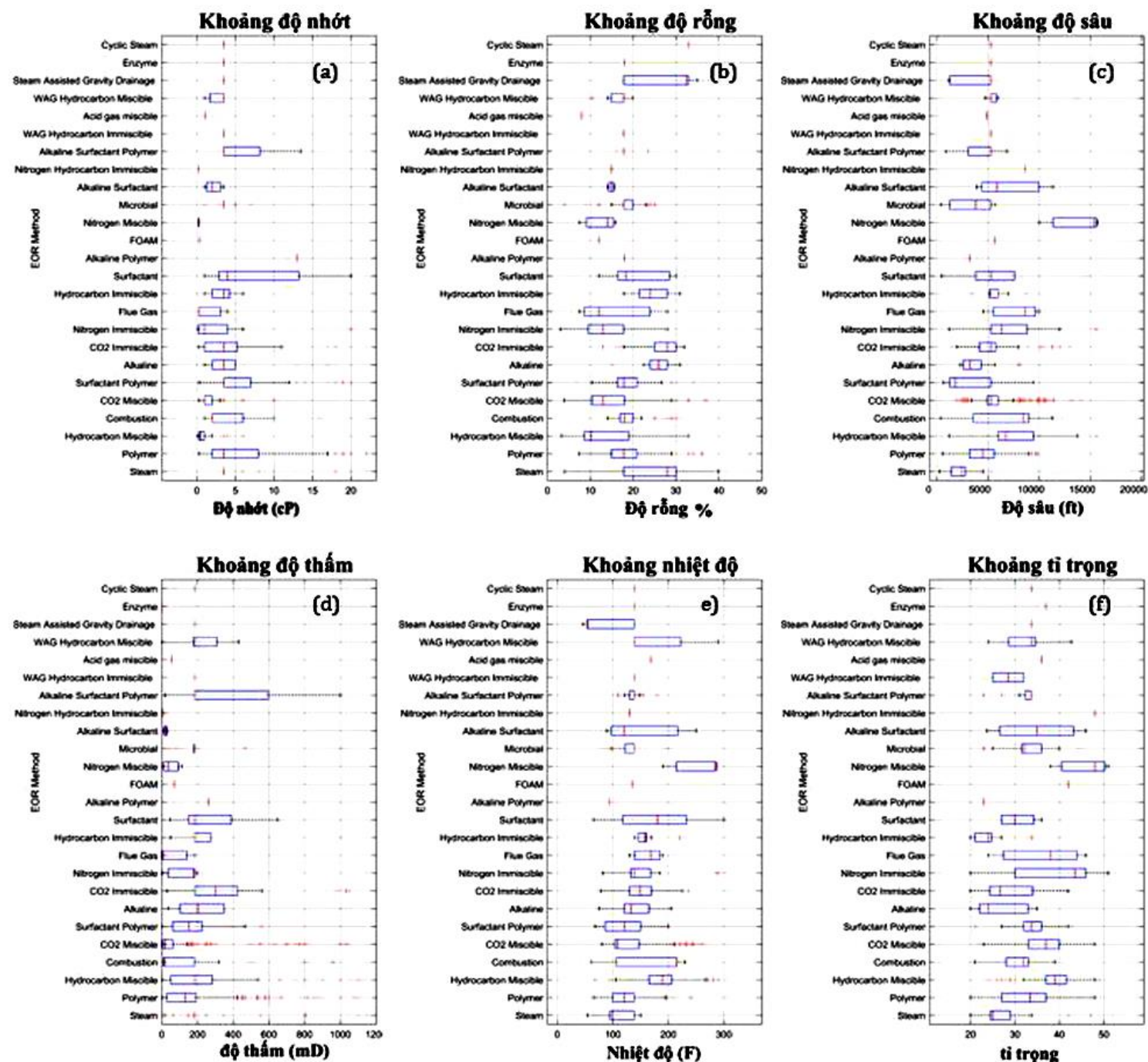

Hình 5. Kết quả chạy phần mềm VPI EOR Screening với các thông số mỏ bằng phương pháp thông thuờng cho đồ thị plotbox về độ nhớt dầu (a), độ rỗng (b), độ sâu (c), độ thấm (d), nhiệt độ (e), tỷ trọng (f) theo tùng phương pháp EOR.

Đa số các mỏ phù hợp với phương pháp bơm ép tác nhân khí (như bơm ép tác nhân khí hydrocacbon trộn lần/không trộn lẫn; bơm ép khí $\mathrm{CO}_{2}$ trộn lẫn/không trộn lẫn) và phương pháp bơm ép tác nhân hóa học như (bơm ép tác nhân hóa học polyme, bơm ép tác nhân hóa học surfactant - polyme, bơm ép tác nhân hóa học surfactant, bơm ép tác nhân hóa học ASP).

\subsection{Kết quả tính toán theo phương pháp nâng cao (Advanced screening)}

Phương pháp nâng cao dựa trên phân tích CSDL bằng các thuật toán Fuzzy, PCA - phân tích thành phần chính, hệ thống hàm phân lọc, thuật toán phân cụm (clustering), học máy, để xác định phương pháp EOR phù hợp với mỏ nghiên cứu.

Phân bố các tham số độ sâu (depth), độ rỗng (por), độ thấm (perm), tỷ trọng (API), độ nhớt (visc), nhiệt độ (temp), độ bão hòa (start_sat) và sản lượng khai thác (T_Prod_log) được thể hiện trên đường chéo của Hình 5 . Phía dưới đường chéo là đồ thị mô tả quan hệ giữa các đại lượng và hệ số tương quan Pearson của các đại lượng biểu diễn ở các ô phía trên đường chéo tương ứng. Theo đó, độ nhớt có tương quan cao với tỷ trọng, hệ số tương quan là 0,92 .

Nhiệt độ cũng tương quan cao với độ sâu, hệ số là 0,83 . Ngược lại, những đại lượng không tương quan với nhau, hệ số tương quan rất nhỏ, thì không nhìn thấy trên Hình 6. Kết quả phân tích 
dữ liệu được đưa ra trên không gian 2 chiều bằng phương pháp PCA và K - means trên Hình 7.

Kết quả nghiên cứu chuyên sâu trên các thuật toán khi áp dụng cho các phương pháp hóa học (Hình 8) cho thấy, các đối tượng nghiên cứu của trầm tích Bể Cửu Long (mỏ A) có xu hướng phù hợp với Cluster 2 (Hình 9). Trong đó, phương pháp bơm ép polymer và phương pháp bơm ép chất hoạt động bề mặt kết hợp polyme (SP) được xếp hạng cao nhất với $28 \%$ và $27 \%$ so với tổng số các phương pháp khác (Hình 10). Kết quả lựa chọn phương pháp tối ưu cho các mỏ là phương

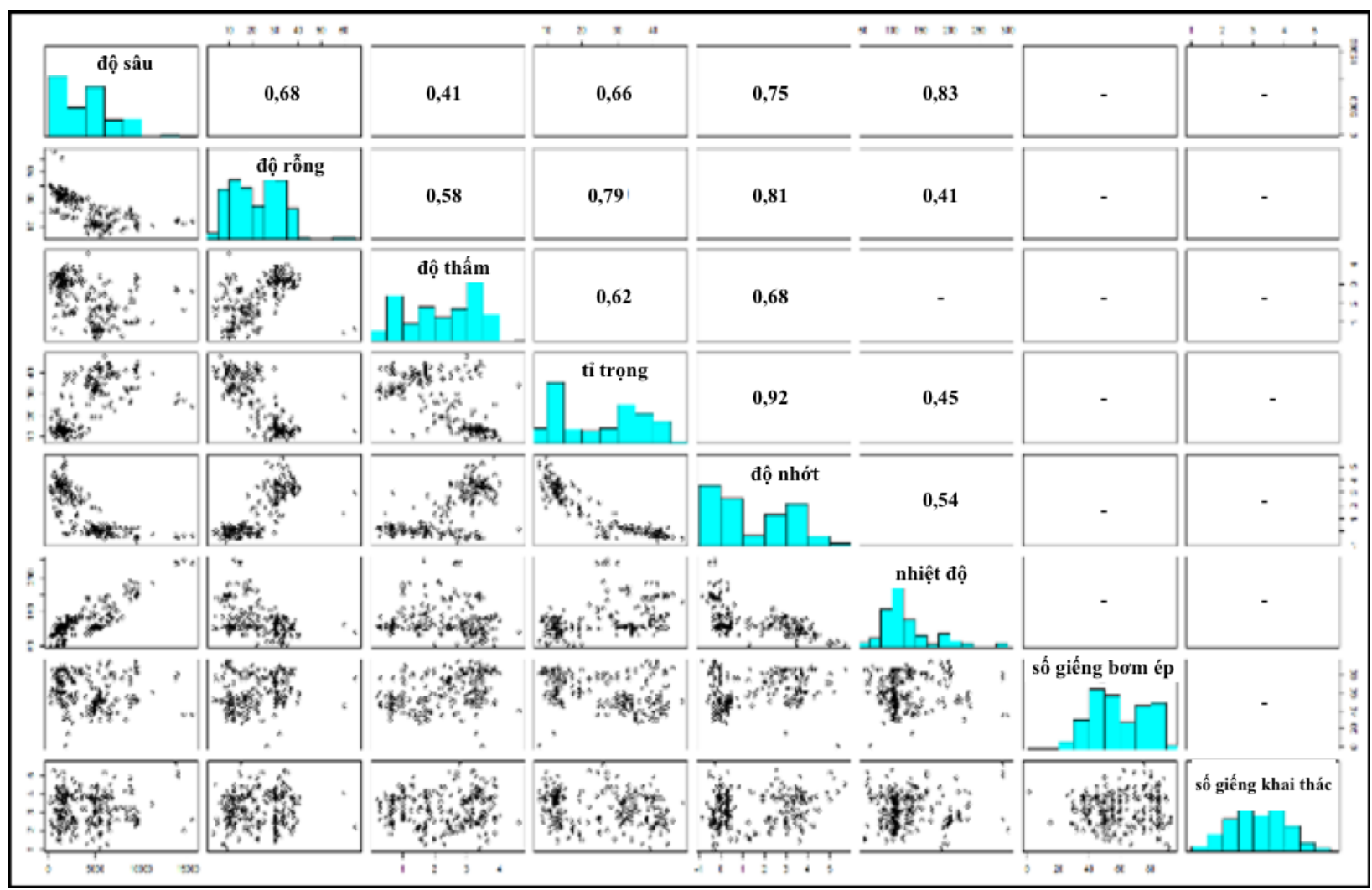

Hình 6. Phân bố các tham số chính và quan hệ tương quan.

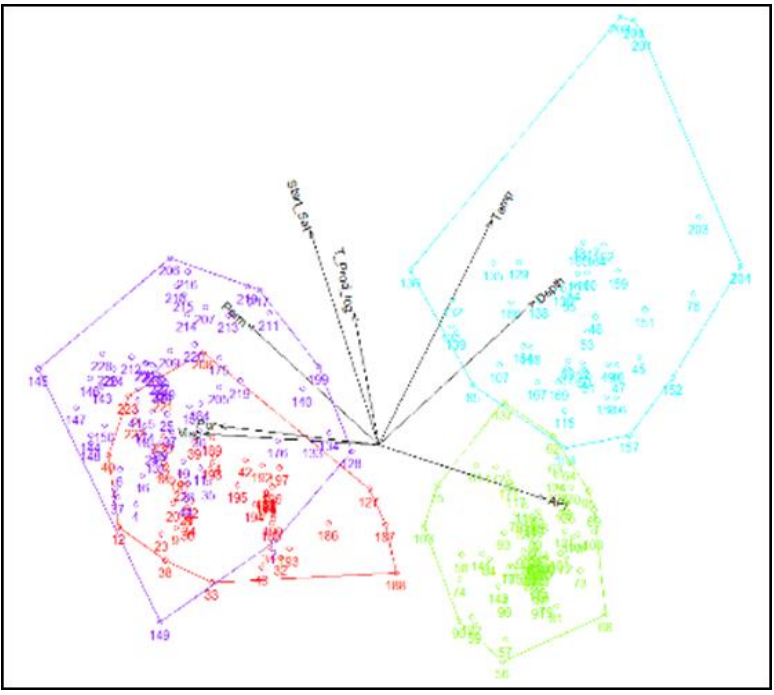

Hình 7. Trực quan dũ liệu trong không gian 2 chiều kết hợp 2 phương pháp PCA và $K$ - means theo các chiều không gian của các thông số mỏ độ.

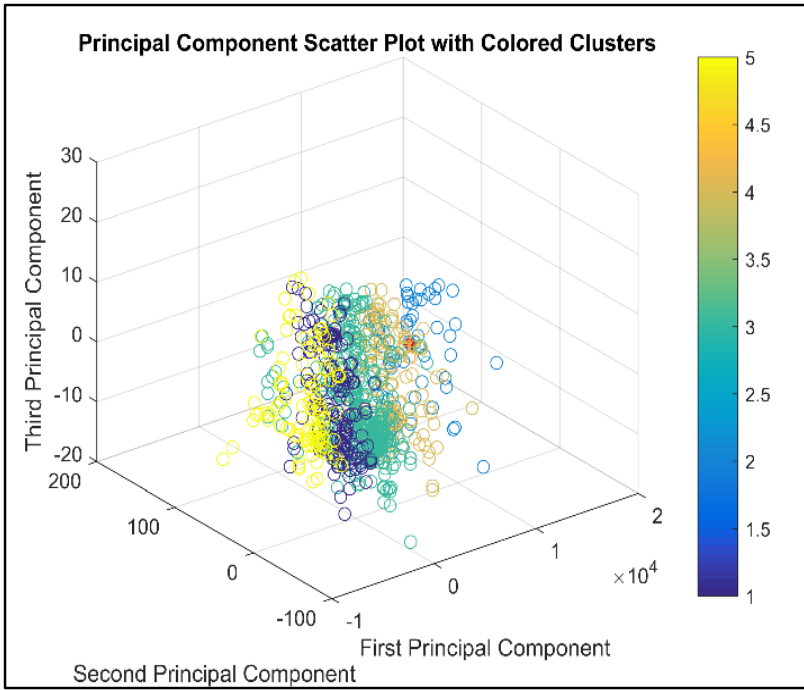

Hình 8. Kết quả chay PCA và $K$ - mean cho mỏ A với cột màu hiển thị là các cluster 1, 2, 3 và màu đỏ là số liệu mỏ A. 
pháp bơm ép polymer hoặc bơm ép SP. Kết quả nghiên cứu chuyên sâu cho mỏ $\mathrm{B}$ trên phần mềm cho thấy, đối tượng trầm tích này có xu hướng phù hợp nhất với các giải pháp bơm ép khí do nằm trong cluster 4. Trong đó, phương pháp bơm ép trộn lẫn Hydrocacbon và không trộn lẫn Hydrocacbon được xếp hạng cao nhất khoảng $43 \%$, sau đó là bơm ép $\mathrm{CO}_{2}$ không trộn lẫn khoảng $26 \%$, các giải pháp hóa phẩm cho kết quả thấp hơn (các Hình 11, 12).

Kết quả nghiên cứu ở mỏ $\mathrm{C}$ cho thấy, các thông số mỏ có xu hướng phù hợp với cluster 3 , thuộc nhóm có thể áp dụng được hai giải pháp khí và hóa. Trong đó, phương pháp bơm ép trộn lẫn và không trộn lẫn Hydrocacbon được xếp hạng cao nhất khoảng 32\%, sau đó là bơm ép polymer khoảng $22 \%$ và bơm ép $\mathrm{CO}_{2}$ không trộn lẫn khoảng 20\% (các Hình 13, 14).

Kết quả phân tích chuyên gia dựa trên đánh giá hiện trạng của mỏ nghiên cứu và các bài học kinh nghiệm từ CSDL cho thấy, với mỏ $\mathrm{A}$ thì giải pháp bơm ép chất hoạt động bề mặt kết hợp polymer sẽ cho hiệu quả kinh tế - kỹ thuật cao nhất. Các mỏ $\mathrm{B}, \mathrm{C}$ với giải pháp bơm ép khí $\mathrm{CO}_{2}, \mathrm{~N}_{2}$ sẽ không khả thi do nguồn khí cung cấp và hệ thống đấu nối sẽ không khả thi do chi phí quá lớn không đảm bảo hiệu quả kinh tế của dự án. Giải pháp bơm ép khí Hydrocarbon đồng hành của mỏ là phù hợp nhất.

\section{Kết luận}

Nghiên cứu đã áp dụng thành công các phương pháp phân tích đánh giá hiện nay trên thế giới từ phương pháp so sánh, tham khảo đến các thuật toán chuyên sâu và đã tích hợp trong phần mềm chuyên ngành của Viện dầu khí Việt Nam (VPI EOR Screening). Kết quả nghiên cứu cho độ tin cậy cao.

Phương pháp nghiên cứu đánh giá thông thường với các thông số vỉa cơ bản của mỏ được so sánh với bảng tiêu chí từ các dự án EOR đã áp dụng thành công. Bộ tiêu chí gồm các thông số cơ bản để áp dụng thông thường bao gồm: tỷ trọng của dầu, độ nhớt của dầu, độ thấm - độ rỗng trung bình vỉa, độ sâu và nhiệt độ, độ bão hòa, thành phần hydrocarbon của chất lưu vỉa, cấu trúc vỉa chứa đã được áp dụng cho các mỏ dầu khí Bể Cửu Long. Kết quả tính toán từ phần mềm cho thấy sự thay đổi của các phương pháp đối với các đối tượng trầm tích Bể Cửu Long là không quá lớn.

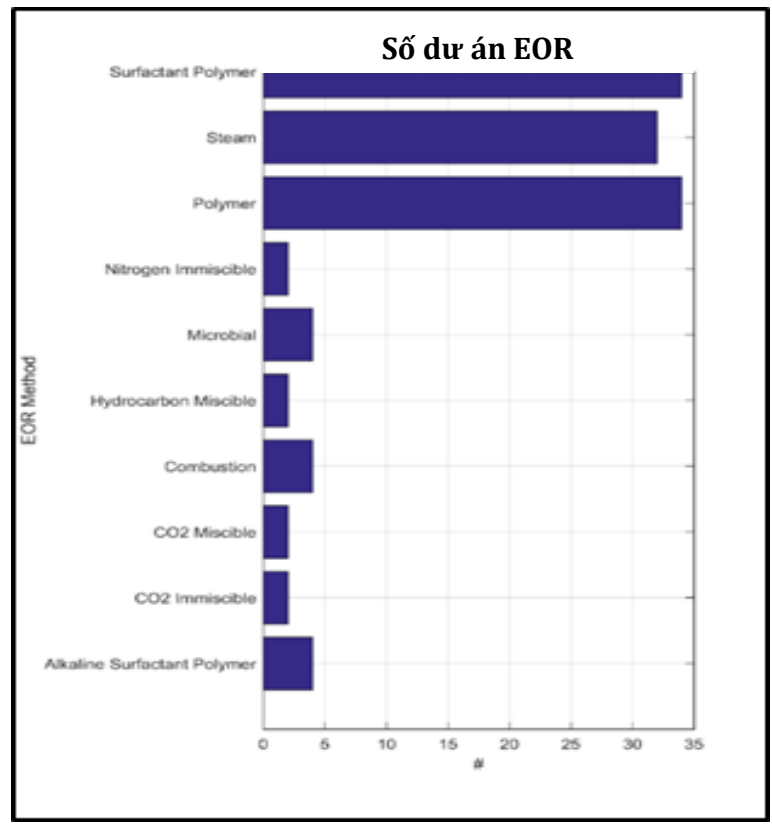

Hình 9. Kết quả thống kê các dự án EOR trên thế giới phù hợ trong Cluster 2 với mối tương quan số dự án EOR và phưong pháp EOR.

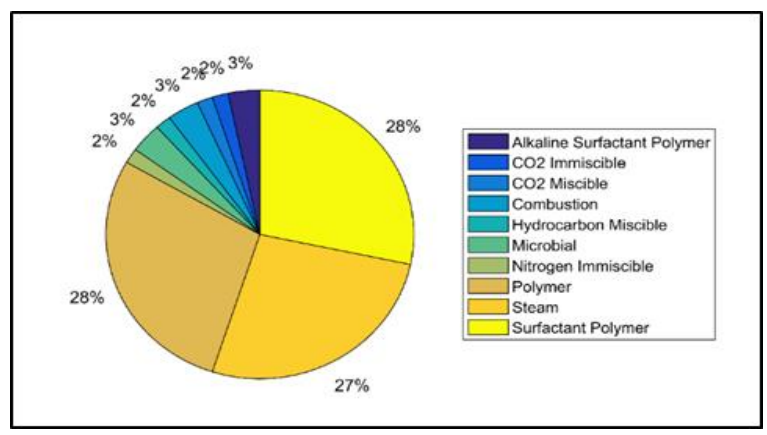

Hình 10. Kết quả lựa chọn phương pháp EOR tối ư cho mỏ $A$.

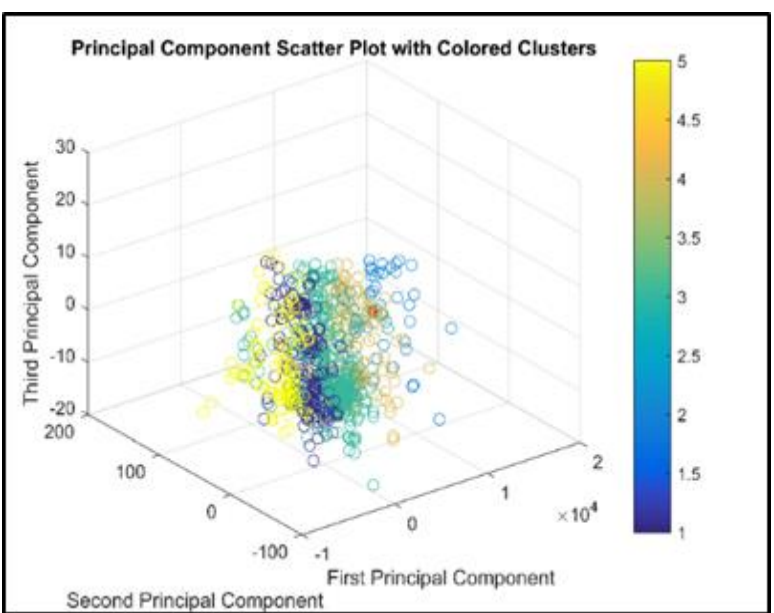

Hình 11. Kết quả chạy PCA và $K$ - mean cho $B$ vớ $i$ cột màu hiển thị là các cluster 1, 2, 3 và màu đỏ là sốliệu mỏ $B$. 


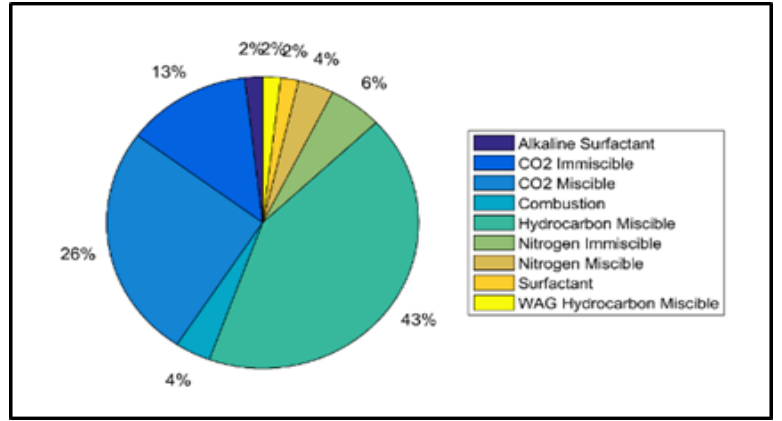

Hình 12. Kết quả lựa chọn phương pháp EOR tối u'u cho $B$.

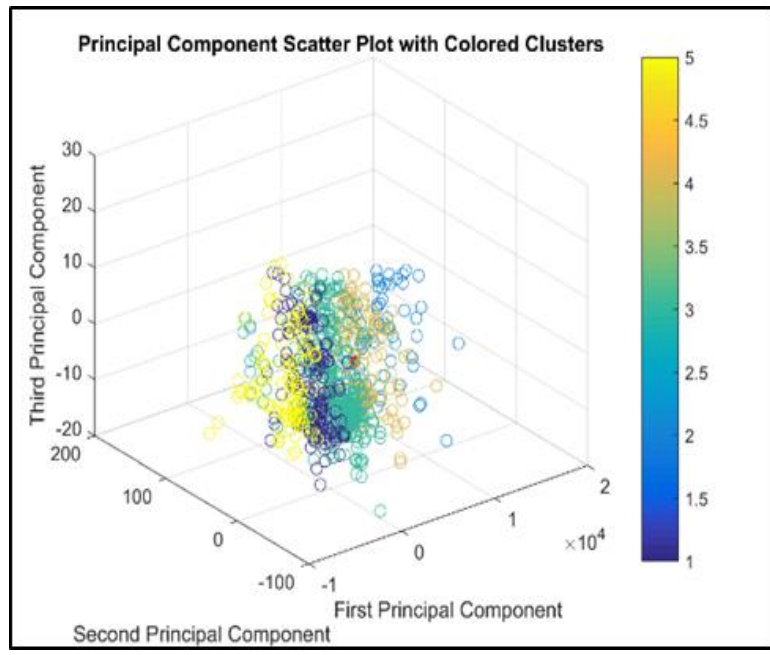

Hình 13. Kết quả chạy PCA và $K$ - mean cho mỏ $C$ với côt màu hiển thi là các cluster 1, 2, 3 và màu đỏ là số liệu mỏ C.

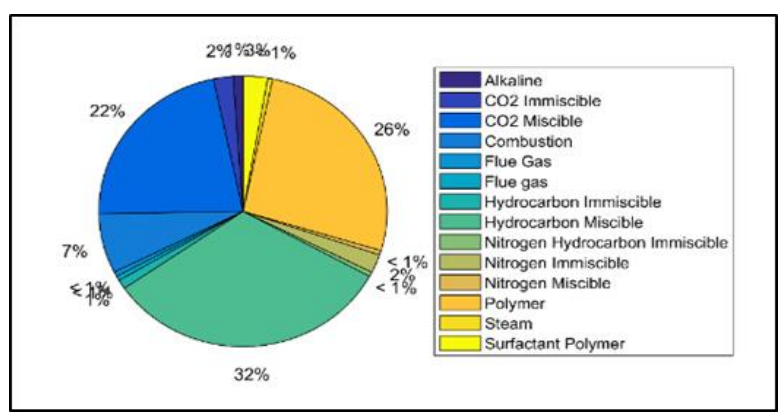

Hình 14. Kết quả lựa chọn phương pháp EOR tối ư cho mỏ $C$.

Phương pháp bơm ép tác nhân khí hydrocacbon, khí $\mathrm{CO}_{2}$ và bơm ép tác nhân hóa học (polyme, chất hoạt động bề mặt, kết hợp) là phù hợp với các mỏ dầu khí Bể Cửu Long.

Phần nâng cao của phần mềm VPI EOR Screening nghiên cứu chuyên sâu về các phương pháp toán học để xử lý/phân tích số liệu như: học máy, trí tuệ nhận tạo, Fuzzy, PCA - phân tích thành phần chính, $\mathrm{K}$ - mean, thuật toán phân cụm (clustering) và kết hợp nghiên cứu chuyên gia để nâng cao chất lượng lựa chọn nhằm xác định chính xác giải pháp phù hợp với mỏ đang nghiên cứu. Phần mềm của Viện dầu khí Việt Nam (VPI EOR Screening) được chạy thử nghiệm cho một số đối tượng trầm tích thuộc Bể Cửu Long đã cho kết quả lựa chọn chính xác và đúng đắn. Kết quả phù hợp với các đánh giá, nhận định trước đó của các nhà nghiên cứu công nghệ mỏ, các chuyên gia EOR và nhà điều hành các mỏ dầu khí.

\section{Lời cảm ơn}

Nhóm tác giả trân trọng cảm ơn Viện Dầu khí Việt Nam, Tập đoàn Dầu khí Việt Nam, Trường Đại học Mỏ - Địa chất, Bộ Khoa học và Công nghệ đã hỗ trợ giúp đỡ chuyên môn, nguồn lực và kinh phí để thực hiện nghiên cứu này. Bài báo là một phần kết quả nghiên cứu của đề tài khoa học và công nghệ cấp Quốc gia "Nghiên cứu lựa chọn các giải pháp công nghệ và thực nghiệm đánh giá các tác nhân nâng cao hệ số thu hồi dầu cho đối tượng trầm tích lục nguyên của các mỏ dầu thuộc Bể Cửu Long", mã số ĐTĐLCN.26/19 và đề tài cấp Viện dầu khí Việt Nam "Nghiên cứu xây dựng CSDL của 200 dự án EOR trên thế giới và phần mềm chuyên ngành để đánh giá, lựa chọn các giải pháp nâng cao hệ số thu hồi dầu".

\section{Đóng góp của các tác giả}

Tác giả Hoàng Long lên kế hoạch, tiến hành thu thập, xử lý số liệu và kiểm tra tiến độ công việc; Trịnh Việt Thắng, Triệu Hùng Trường tham gia nghiên cứu lựa chọn thông số mỏ cho các mỏ ở Việt Nam. Nguyễn Minh Quý, Phạm Quý Ngọc, Đoàn Huy Hiên thiết kế, viết thuật toán Clustering, $\mathrm{K}$ - means, Fuzzy, AI và xây dựng phần mềm. Hoàng Linh thu thập số liệu và chỉnh sửa nội dung.

\section{Tài liệu tham khảo}

Al - Adasani A., Bai B., (2010). Recent Developments and Updated Screening Criteria of Enhanced Oil Recovery Techniques. Society of Petroleum Engineers, 51 - 60.

Guerillot D. R. (1988). EOR Screening With an Expert System. Society of Petroleum Engineers, 137 - 142. 
Hoàng Long. (2021). Nghiên cứu lựa chọn các giải pháp công nghệ và thực nghiệm đánh giá các tác nhân nâng cao hệ số thu hồi dầu cho đối tượng trầm tích lục nguyên của các mỏ dầu thuộc bể Cửu Long. Đe tài Độc lập cap Nhà nước của Bộ KHCN, mã số ĐT ĐLCN.26/19. Viện dầu kh Việt Nam.

Hoàng Long (2020). Nghiên cúu xây dựng cơ sở dư liệu của 200 dự án EOR trên thế giới và phần mềm chuyên ngành để đánh giá, lựa chọn các giải pháp nâng cao hệ số thu hồi dầu. Đề tài cấp Viện dầu khí Việt Nam, mã số 5338.VDKVN.

Poettmann F. H., Hause,W. R. (1978). Micellar Polymer Screening Criteria And Design. Society of Petroleum Engineers, 102 - 110.

Ramos. G. A. R., \& Akanji. L. (2017). Application of artificial intelligence for technical screening of enhanced oil recovery methods. Journal of Oil, Gas and Petrochemical Sciences, 57-64.

Siena Martina, Guadagnini Alberto (2016). A Novel EOR Screening Approach based on Bayesian Clustering and Principal Component Analysis. SPE Res Eval \& Eng, 19(03), 382-390.

Taber J. J., Martin, F. D., Seright, R. S., (1997). EOR Screening Criteria Revisited - Part 1: Introduction to Screening Criteria and Enhanced Recovery Field Projects. Society of Petroleum Engineers, 189-198.

Zhang Na. (2015). Steam flooding screening and EOR prediction by using clustering algorithm and data visualization. Masters Theses. 488p. 